\title{
Éditorial
}

\section{Fin d'une revue littéraire}

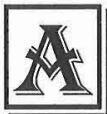

près trente-neuf numéros parus depuis 1989, voici le quarantième, le dernier. LittéRéalité achève ses saisons.

Désignée « une revue d'écrits originaux et de critique », bilingue, elle s'est affirmée peu à peu comme une voix libre, ouverte, multiple et autoritaire dans le domaine des lettres françaises et francophones. On a publié de nombreux articles, comptes rendus et poèmes inédits. On a encouragé la contribution de jeunes critiques et de jeunes poètes. On est fier surtout d'avoir accueilli plusieurs grands poètes de notre époque, parmi lesquels figurent Bonnefoy, Deguy, Chedid, Guillevic et le Québécois Renaud Longchamps.

Dès le début, notre mission nous engageait à faire connaître la bourgeonnante littérature franco-ontarienne. Je l'ai fait avec vigueur et enthousiasme pendant les années 90 . Puis vint le désenchantement et je déclarais cette littérature moribonde, un déclin inévitable que j'attribuais à trois forces destructrices : la médiocrité d'un grand nombre de textes publiés grâce l'autofinancement des auteurs ou les subventions publiques; une critique débile, souvent partisane et incestueuse; et un lectorat presque inexistant. Veuille que je me sois trompé!

LittéRéalité atteint son couchant mais elle ne laisse pas de vide. Elle occupera un espace utile sur les rayons de nombreuses bibliothèques universitaires.

Je lève donc un toast à cette revue et je remercie de tout cœur tous ceux qui ont contribué à sa réussite avec leur travail, leur créativité et leur générosité.

Sergio Villani 